\title{
Review of maternal mortality in a tertiary care urban teaching hospital: 10 year retrospective study
}

\author{
Shobha G.*, Jayashree V. Kanavi, Veena B. Divater, Annamma Thomas
}

Department of Obstetrics and Gynecology, St. Johns Medical College Hospital, Bengaluru, Karnataka, India

Received: 11 March 2019

Accepted: 09 April 2019

*Correspondence:

Dr. Shobha G,

E-mail: shobhag76@yahoo.com

Copyright: () the author(s), publisher and licensee Medip Academy. This is an open-access article distributed under the terms of the Creative Commons Attribution Non-Commercial License, which permits unrestricted non-commercial use, distribution, and reproduction in any medium, provided the original work is properly cited.

\begin{abstract}
Background: The objectives of this study were to calculate the maternal mortality ratio, causes for maternal death in our institution and the duration of hospital admission to death interval.

Methods: The study included collecting and analyzing the details of maternal death in women who were admitted to St. Johns Medical College Hospital, Bengaluru, from January 2007 to December 2016.

Results: Total maternal deaths were 61 and live births were 26,001 during the study period. The maternal mortality ratio (MMR) was 234.6 per 100,000 live births. Majority of maternal deaths occurred in women aged 18 - 35 years 56 $(91.80 \%)$ women, primipara $45(73.77 \%)$ and referred cases to our institution from other hospitals $52(85.24 \%)$. Most of the women died in the postnatal period 54 (88.52\%). Direct obstetric causes accounted for 44 (72.13\%) maternal deaths and indirect causes $17(27.86 \%)$ deaths. Preeclampsia and eclampsia were the leading causes for death $13(21.31 \%)$ followed by acute fatty liver of pregnancy $12(19.67 \%)$, hemorrhage $7(13.11 \%)$ and sepsis 6 (9.83\%). Anemia was present in $77.04 \%$ of women at the time of admission to our hospital. Thirty six (59.01\%) women died within a week of admission to the hospital, in which 13 (21.31\%) women died in less than 24hours of admission. Twenty five (40.98\%) women died after a week of admission to hospital.

Conclusions: Apart from the triad of preeclampsia, obstetric haemorrhage and sepsis, acute fatty liver of pregnancy has emerged as an important cause of maternal death. Most of the maternal deaths are preventable. Early detection of complications and timely referral to tertiary care hospital in St. Johns Medical College Hospital, Bengaluru, Karnataka, India decreases maternal morbidity and mortality.
\end{abstract}

Keywords: Acute fatty liver of pregnancy, MMR, Preeclampsia, Obstetric haemorrhage, Sepsis

\section{INTRODUCTION}

Childbirth is a memorable event in a woman's life. It can turn into nightmare in no time. Hence the term normal delivery is a retrospective diagnosis. Maternal death has a devastating effect on the family especially for her surviving new born and other children.

According to WHO, a maternal death is defined as "the death of a woman while pregnant or within 42 days of termination of pregnancy, irrespective of the duration and site of pregnancy, from any cause related to or aggravated by pregnancy or its management but not from accidental or incidental causes. ${ }^{1}$ Maternal mortality ratio (MMR) is defined as number of maternal deaths during a given time period per 100,000 live births during the same timeperiod. $^{1}$ MMR in India is 130 per 100,000 live births in 2014-2016. ${ }^{2}$ The important causes for maternal mortality according to 1997-2003 SRS survey are hemorrhage $(38 \%)$, sepsis $(11 \%)$, hypertension $(5 \%)$, abortion $(8 \%)$, obstructed labor (5\%) and other conditions (34\%). Anemia (19\%) is a leading cause of death and also an aggravating factor in hemorrhage, preeclampsia and sepsis. $^{3}$

MMR indicates healthcare situation and health care 
policy of a country. India is one of the countries with high maternal mortality rate. Goal of SDG is to reduce MMR to70 by $2030 .{ }^{4}$ At present India's MMR is on declining trend as per goal set by MDG5. 2,5

In this review we studied the maternal deaths in our institutions and measures to prevent the same.

\section{METHODS}

The study was conducted at St. Johns Medical College and Hospital (SJMCH), Bengaluru, which is a tertiary care center catering patients from Bengaluru, other districts of Karnataka and neighboring states of Andhra Pradesh, Telangana and Tamil Nadu. The study included collecting and analyzing the details of maternal death in women who were admitted to St. Johns Medical College Hospital, Bengaluru, from January 2007 to December 2016. Antenatal, labor records, ICU records, operative notes and death records were reviewed. Demographic variables like age, parity, gestational age, delivery details, complications, any interventions, causes of death and admission to death interval were studied. We excluded maternal deaths occurring 42 days after termination of pregnancy and due to accident, homicide or suicide.

\section{Statistical analysis}

Data will be presented as descriptive statistics including mean and percentage.

\section{RESULTS}

During the study period there were 26,001 live births and 61 maternal deaths. Maternal mortality ratio was 234.6/100,000 live births.

In the present study the maximum number of maternal deaths $56(91.80 \%)$ occurred in the age group of 18-35 years. Majority were primipara $45(73.77 \%)$ (Table 1$)$. Most of the women $52(85.24 \%)$ were referred to our institution from other hospitals. Two pregnant women were booked regularly at our institution (3.27\%), one had severe preeclampsia with pulmonary edema and another had auto immune hepatitis with liver cirrhosis. Three $(4.91 \%)$ women were unbooked.

Fifty four $(88.52 \%)$ women died in the postnatal period. There were 3 undelivered women (4.91\%). Most of them had vaginal delivery $28(45.90 \%)$ (Table 1$)$. The major causes of death were direct obstetric causes $44(72.13 \%)$ (Table 2). Preeclampsia and eclampsia 13 (21.31\%), acute fatty liver of pregnancy $12(19.67 \%)$, obstetric hemorrhage $7(13.11 \%)$ and sepsis $6(9.83 \%)$ accounted for important direct causes of death. Seventeen women $(27.86 \%)$ died due to indirect causes. Most common indirect causes of death were viral hepatitis $3(4.91 \%)$, cardiac diseases $3(4.91 \%)$, H1N1 influenza $3(4.91 \%)$ and leukemia $2(3.27 \%)$. Anemia was present in $77.04 \%$ of patients at the time of admission to our hospital.
Table 1: Demographic details.

\begin{tabular}{|ll|}
\hline Characteristics & Number $(\%) \mathbf{n = 6 1}$ \\
\hline Age (years) & $1(1.63)$ \\
\hline$<18$ & $56(91.80)$ \\
\hline $18-35$ & $4(6.55)$ \\
\hline$>35$ & $45(73.77)$ \\
\hline Parity & $13(21.31)$ \\
\hline Primipara & $3(4.91)$ \\
\hline Multipara & \\
\hline Grandmulti & $2(3.27)$ \\
\hline Booking status & $4(6.55)$ \\
\hline Booked at institution & $3(4.91)$ \\
\hline $\begin{array}{l}\text { Late booking (3rd trimester) at } \\
\text { institution }\end{array}$ & $52(85.24)$ \\
\hline Unbooked & \\
\hline Referred from elsewhere & $54(88.52)$ \\
\hline Delivery status & $33(54)$ \\
\hline Total delivered women & $21(34.4)$ \\
\hline Delivered at our institution & $4(6.55)$ \\
\hline Delivered outside & $3(4.91)$ \\
\hline Abortions & $28(45.90)$ \\
\hline Undelivered & $2(3.27)$ \\
\hline Mode of delivery & $24(39.34)$ \\
\hline Vaginal & \\
\hline Instrumental & \\
\hline LSCS & \\
\hline
\end{tabular}

Table 2: Causes for maternal death.

\begin{tabular}{|ll|}
\hline Causes of death & Number (\%) $n=61$ \\
\hline Direct causes & $\mathbf{4 4}(\mathbf{7 2 . 1 3})$ \\
\hline Preeclampsia and eclampsia & $13(21.31)$ \\
\hline Acute fatty liver of pregnancy & $12(19.67)$ \\
\hline Obstetric hemorrhage & $7(13.11)$ \\
\hline Sepsis & $6(9.83)$ \\
\hline Peripartum cardiomyopathy & $2(3.27)$ \\
\hline Pulmonary thromboembolism & $2(3.27)$ \\
\hline Incomplete abortion & $1(1.63)$ \\
\hline Molar pregnancy & $1(1.63)$ \\
\hline Indirect causes & $\mathbf{1 7}(\mathbf{2 7 . 8 6})$ \\
\hline Viral Hepatitis & $3(4.91)$ \\
\hline Cardiac diseases & $3(4.91)$ \\
\hline H1N1 influenza & $3(4.91)$ \\
\hline Leukemia & $2(3.27)$ \\
\hline Portal hypertension & $1(1.63)$ \\
\hline Dengue fever & $1(1.63)$ \\
\hline Immune thrombocytopenia & $1(1.63)$ \\
\hline Chronic liver disease & $1(1.63)$ \\
\hline Anaphylactic shock & $1(1.63)$ \\
\hline Hemolytic uremic syndrome & $1(1.63)$ \\
\hline
\end{tabular}

Admission to death interval analysis showed that most women $36(59.01 \%)$ died within a week of admission to our hospital, among these $13(21.31 \%)$ women died in less than twenty fours of admission. Twenty five 
$(40.98 \%)$ women died after a week of admission to the hospital (Table 3).

Table 3: Admission to death interval

\begin{tabular}{|ll|}
\hline Admission to death interval & Number $(\%) \mathrm{n}=61$ \\
\hline$<24$ hours & $13(21.31)$ \\
\hline $24-72$ hours & $11(18.03)$ \\
\hline $4-7$ days & $12(19.67)$ \\
\hline$>7$ days & $25(40.98)$ \\
\hline
\end{tabular}

All of them received ICU care and supportive treatment. As seen from Table 4, 23 (37.70\%) patients received multiple blood and blood product transfusion and 19 $(31.1 \%)$ patients underwent dialysis. Various surgical intervention in the form of B-Lynch suture $5(8.19 \%)$, relaparotomy $4(6.55 \%)$, hysterectomy $3(4.91 \%)$, tracheostomy $3(4.91 \%)$, and hemicraniotomy $2(3.27 \%)$ were done.

Table 4: Interventions performed.

\begin{tabular}{|ll|}
\hline $\begin{array}{l}\text { Interventions } \\
\text { Multiple blood and blood } \\
\text { products transfusions }\end{array}$ & $23(37.70)$ \\
\hline Dialysis & $19(31.14)$ \\
\hline B-Lynch suture & $5(8.19)$ \\
\hline Relaparotomy & $4(6.55)$ \\
\hline Hysterectomy & $3(4.91)$ \\
\hline Tracheostomy & $3(4.91)$ \\
\hline Hemi-craniotomy & $2(3.27)$ \\
\hline
\end{tabular}

\section{DISCUSSION}

The MMR of our institution is 234.6 per 100,000 live births. It is high compared to national MMR which is 130 per 100,000 live births. Our institution being a tertiary care center is the reason for high MMR. Other studies show varying rate of MMR: Khumanthem et al, is 90.45, Hiralal K et al is 147, Rajeshwari et al is 544, Jadhav CA et al, is 395, Saini V et al, is 358.69, Shannon Fernandes et al, is $144.86 .^{6-11}$

The maximum number of maternal death $56(91.80 \%)$ occurred in the age group of 18-35 years which is comparable to other studies. ${ }^{9-11}$ In contrast a study by Khumathem et al, shows highest maternal death in the age group of 30-40 years. ${ }^{6}$ In our study primipara were 45 , accounting for $73.77 \%$ of deaths and grandmulties were $3(4.91 \%)$. In contrast other two studies multipararous women accounted for $75 \%$ and $64.78 \%$ of maternal death. ${ }^{6,10}$ In the same studies grandmulties had a considerable share of $20 \%$ and $19.71 \%$ in maternal deaths. ${ }^{6,10}$ This shows that pregnancy of any order carries the risk of morbidity and mortality. Hence all pregnancies need equal attention and care.

In our study $52(85.24 \%)$ women were referred to our institution from other hospitals. It is similar to other studies: $68.8 \%$ and $73.8 \% .^{8,11}$ Many women had two to three referrals and admissions in other hospitals before reaching our institution wasting precious time.

In our study $3(4.91 \%)$ patients were unbooked and rest all were booked. Only 2 patients were regularly booked in our institution. It is comparable to a study by Jadhav CA et al, where $78.48 \%$ of patients were booked. ${ }^{8}$ Studies by Khumanthem et al, and Shannon et al, shows only $22.5 \%$ and $26.2 \%$ patients were booked respectively. ${ }^{6,11}$ This shows that not just booking but early detection of risk factors, suitable action and timely referral are very important to decrease morbidity and mortality.

Most of the deaths occurred in the postpartum period 54 $(88.52 \%)$ which is comparable to other studies - $69.2 \%$, $66.1 \%$ and $80.95 \% .^{8,10,11}$ Some complications may appear during labor or postpartum period, hence intense monitoring is needed in the fourth stage of labor and postpartum period.

Direct obstetric causes were responsible for 44 (72.13\%) deaths. This is similar to other studies. ${ }^{6-10}$ Preeclampsia and eclampsia were the leading cause for death 13 (21.31\%) followed by acute fatty liver of pregnancy 12 $(19.67 \%)$, hemorrhage $7(13.11 \%)$ and sepsis $6(9.83 \%)$. Seventeen women $(27.86 \%)$ died due to indirect causes. Most common indirect causes of death were viral hepatitis $3(4.91 \%)$, cardiac diseases $3(4.91 \%)$, H1N1 influenza $3(4.91 \%)$ and leukemia $2(3.27 \%)$. Anemia was present in $77.04 \%$ of patients at the time of admission to our hospital. Triad of haemorrhage, preeclampsia and sepsis constituted the main causes of death in all studies. ${ }^{6-11}$ Early detection of preeclampsia, monitoring, use of antihypertensives and magnesium sulphate and timely delivery prevents major maternal morbidity and mortality. The deaths due to preeclampsia related cases in our study mainly occurred due to failure to detect associated complications, timely termination of pregnancy and delayed referral to tertiary care centre. Detection of antepartum hemorrhage and further management, referral to tertiary care center, active management of third stage of labor, detection of postpartum hemorrhage, use of oxytocics, intravenous fluids, blood and blood products and appropriate surgical intervention prevents many haemorrhage related maternal deaths. The women who died of hemorrhage related cause have reached our institution very late or in the stage of irreversible shock. Management of acute fatty liver of pregnancy includes delivery, use of blood and blood products and supportive treatment in intensive care unit. In our institution maternal mortality and morbidity were high in case of acute fatty liver of pregnancy despite above measures.

Admission to death interval analysis showed that most of the women died within a week of admission 36 (59.01\%), among these $13(21.31 \%)$ women died witin twenty four hours of admission to hospital. Twenty five (40.98\%) women died after a week. In contrast other studies 
showed early death: $60 \%, 46.83 \%$ and $35.7 \%$ within 24hours of admission. ${ }^{6,9,11}$ In one study $38.1 \%$ women died after 72 hours. ${ }^{11}$ Availability of good ICU care with multidisciplinary team and blood bank facility in our institution has prolonged the admission to death interval. All patients received ICU admission, supportive care and interventions when required. All these measures have prolonged the life compared to other studies. These facilities have prevented death in many women. We have also observed discharge against medical advice of the patients by relatives in case of poor prognosis and prolonged duration of ICU stay.

\section{CONCLUSION}

Many causes of maternal morbidity and mortality are preventable. Regular antenatal care, early detection of high risk factors, complications and timely intervention and referral to a tertiary care hospital and institutional delivery is needed. Detection of obstetric hemorrhage and hypertensive disorders of pregnancy and appropriate management of the same saves many lives. Aseptic precautions during operative procedures, use of antibiotics and proper operative technique will minimize sepsis. Women should be educated about availability of medical termination of pregnancy services, which prevents unsafe abortions. Detection of early pregnancy complications and proper management decreases maternal deaths. Maternal death should be reviewed in hospitals and pitfalls in the management have to be discussed without blame. Confidential enquiry of maternal death is needed at the state level. Nutrition, hygiene, education and empowerment of the girl child and women are the need of the hour. Late marriage, contraceptive use, spacing pregnancy and limiting family size decreases maternal death considerably. Apart from medical intervention, social, cultural, education, financial factors, public transport, availability of twenty four hours blood bank facility even at periphery and infrastructure plays crucial role in decreasing maternal death. Sincere implementation of the existing health care policies has a huge impact on improving the health status of the population, thus in turn decreasing the maternal morbidity and mortality.

Funding: No funding sources Conflict of interest: None declared

Ethical approval: The study was approved by the Institutional Ethics Committee

\section{REFERENCES}

1. WHO. Maternal mortality ratio (per 100000 live births). WHO. Available at: http://www.who.int/healthinfo/statistics/indmaternal mortality/en/.

2. MMR Bulletin-2014-16. pdf. Available at: http://www.censusindia.gov.in/ vital_statistics/SRS_Bulletins/MMR\%20Bulletin2014-16.pdf.

3. RGI-CGHR-Maternal-Mortality-in-India1997-2003.pdf. Available at; http://www.cghr.org/ wordpress/wp-content/uploads/RGI-CGHR-Maternal -Mortality-in-India-1997\%E2\%80\%932003.pdf.

4. Goal 3: Sustainable Development Knowledge Platform [Internet]. [cited 2018 Jul 5]. Available from: https://sustainabledevelopment.un.org/sdg3.

5. Achievements Under Millennium Development Goals. Available at: http://pib.nic.in/newsite/Print Release.aspx?relid=123669.

6. Khumanthem PD, Chanam MS, Samjetshabam RD. Maternal mortality and its causes in a tertiary center. J Obstet Gynaecol India. 2012;62(2):168-71.

7. Konar H, Chakraborty AB. Maternal Mortality: A FOGSI Study (Based on Institutional Data). J Obstet Gynaecol India. 2013;63(2):88-95.

8. Rajeswari, Shobha. Maternal Mortality in an Urban Tertiary Care Hospital of South India. Indian J Obstet Gynaecol Res. 2016;3(1):32-7.

9. Jadhav CA, Prabhakar G, Shinde MA, Tirankar VR. Maternal mortality: five year experience in tertiary care centre. Indian J Basic Applied Med Res. 2013;7(2):702-9.

10. Saini V, Gupta M. Review of maternal mortality in an urban tertiary care hospital of North India. Int $\mathbf{J}$ Basic Applied Med Sci. 2014;4(1):59-64.

11. Fernandes S, Prabhu P, D’Cunha P. Maternal Mortality at a tertiary care teaching hospital in South India: 10 year retrospective study. Int J Med Health Sci. 2015;3(4):327-31.

Cite this article as: Shobha G, Jayashree VK, Veena BD, Thomas A. Review of maternal mortality in a tertiary care urban teaching hospital: 10 year retrospective study. Int $\mathrm{J}$ Reprod Contracept Obstet Gynecol 2019;8:2050-3. 